\title{
Are non-monetary payment modes more uncertain for stated preference elicitation in developing countries?
}

\author{
Godwin K. Vondolia $^{\text {a, *, Ståle Navrud }}{ }^{\mathrm{b}}$ \\ ${ }^{a}$ Norwegian College of Fishery Science, UiT The Arctic University of Norway, Box 6050, 9037 Troms $\phi$, Norway \\ ${ }^{\mathrm{b}}$ School of Economics and Business, Norwegian University of Life Sciences, Aas, Norway
}

\section{A R T I C L E I N F O}

\section{JEL classification:}

Q50

Q51

Q54

Q56

\section{Keywords:}

Flood insurance

Payment vehicle

Scale parameter

Error components model

\begin{abstract}
A B S T R A C T
An increasing number of stated preference studies adopt both monetary and non-monetary payment modes to elicit preferences for goods and services in developing and transition countries. The extent to which these alternative payment modes approximate the underlying human preferences for these goods and services is poorly understood. The circumstances under which monetary and non-monetary welfare measures can be combined for efficient estimation of welfare measures and to guide public resource allocation also remain unclear. In a split-sample design, we present a choice experiment on the purchase of flood insurance in which insurance premiums are paid in money, labour time and harvests. We use an integrated choice-modeling framework to test for differences in relative scale parameters among these three alternative payment modes. We find that the relative scale parameters for non-monetary payment modes are lower than the relative scale for monetary payment mode. We argue that the two non-monetary payment modes exhibit higher degrees of uncertainties in the choice experiment. We discuss possible causes and the implications of these results for the design of stated preference studies and the use of resulting welfare measures in cost-benefit analyses.
\end{abstract}

\section{Introduction}

The use of non-monetary numeraires to elicit stated preferences for non-market goods and services has been in vogue in developing and emerging countries for over two decades. Some of the early uses of non-monetary payment modes in stated preferences include Swallow and Woudyalew (1994); Shyamsundar and Kramer (1996) and Echessah et al. (1997). The main motivation for using the nonmonetary numeraires in these earlier applications is to present scenarios that are more familiar and realistic in economies with high degrees of subsistence (Whittington, 2010). For instance, Shyamsundar and Kramer (1996) use rice to value tropical rainforest protection among local peoples of Madagascar as cash transactions are uncommon among these peoples. However, recent studies have provided additional arguments to suggest that non-monetary numeraires are, in fact, more preferable to monetary exchanges for nonmarket goods and services in these countries. For instance, Asquith et al. (2008) find that respondents prefer non-monetary payments to monetary payments in exchange for environmental services. Moreover, Brouwer et al. (2008) show in a follow-up survey that zero monetary bids can be eliminated in stated preference studies by the adoption of non-monetary numéraires. Furthermore, O'Garra (2009) suggests that the respondents with lexicographic preferences may find non-monetary exchanges such as time more acceptable in exchange for environmental goods and services. These factors may account for the further uses of non-monetary numeraires for stated

\footnotetext{
* Corresponding author.

E-mail addresses: godwin.k.vondolia@uit.no (G.K. Vondolia), stale.navrud@nmbu.no (S. Navrud).
} 
preference elicitation in developing countries (see e.g. Brouwer et al., 2008; O'Garra, 2009; Rai and Scarborough, 2013; Vondolia et al., 2014; Gibson et al., 2016).

The increasing use of non-monetary payment modes for stated preference elicitation often in parallel with monetary payment modes raises questions regarding which of these payment modes produce good approximations of the underlying welfare measures. From a standard economic theory, largely based on time allocation model (Becker, 1965), one can deduce that the payment mode should be irrelevant to the estimation of welfare measures. This is because different payment modes are convertible as have been demonstrated by studies that derive welfare measures for different payment modes (see Larson and Shaikh, 2002; Eom and Larson, 2006). However, Lee et al. (2015) conclude from experimental studies that decisions in money and time domains influence the stability of consumer preferences. Specifically, Lee et al. (2015) observe that decisions in money are processed analytically and decisions in time are processed affectively. The insight is that there are qualitative differences in the processing of decisions in money and time; and thus consumer preferences are unstable.

The adoption of different payment modes in stated preference elicitation has bearings on resource allocations decisions. One of the main uses of stated preferences is to provide welfare measures for use in cost-benefit analyses (see Navrud and Pruckner, 1997). Theoretically, the use of non-monetary numeraires in evaluations have long been noted to depend on whether good is question is a public good or private good (see e.g. Brekke, 1997; Dreze, 1998). Specifically, Brekke (1997) notes that the choice of numéraire matters in the evaluation of public goods provision but not in the purchase of private goods. This is because the choice of numéraires requires normalization of prices and marginal utility; and these normalizations make the choice of numéraires to matter for public goods but not for private goods (Brekke, 1997). In addition, Dreze (1998) assesses the consequences of numéraire for private goods, and notes that under market imperfections e.g. rationing and market segmentation, the choice of numéraire matters for private goods as well. On this account, one would be interested to know the implications of conducting stated preferences in monetary and non-monetary payment modes in order to address some of the effects of payment modes in project evaluations using different numeraires.

A number of studies have investigated the effects of using non-monetary numeraires rather than monetary payments largely based on contingent valuation (CV) studies. The CV studies that compare non-monetary payment modes with monetary payment modes often find that respondents are more likely to state a positive willingness-to-pay (WTP) under non-monetary payment modes (see e.g. Brouwer et al., 2008; Vondolia et al., 2014). Vondolia et al. (2014) attribute some of these disparities in CV responses to experience with these modes of payments. In many of these studies, the respondents usually prefer to contribute time rather than contribute money (Whittington et al., 1990). Consequently, the welfare estimates from CV studies have been found to be higher under non-monetary numeraires. For example, Echessah et al. (1997) use the average wage rate of a casual worker to convert WTP in time into monetary measure and observe that the mean WTP is higher when labour payment mode is used. O'Garra (2009) finds in a CV study on the valuation of fishing grounds that willingness to contribute time is three time higher than WTP estimated in monetary value when the adjusted wage rate is used to convert the willingness to contribute time into monetary value. In a choice experiment, Rai and Scarborough (2013) find that the shadow value of household labour is lower than the market wage rate among farm households.

The above anomalies have been used to question the extent to which resultant non-monetary welfare measures can be used to evaluate the allocation of scarce resources. The main thrust of this criticism is an assessment of the use of non-monetary payment vehicles by Ahlheim et al. (2010, 2017) who present theoretical and empirical results to argue that the adoption of alternative payment modes such as labour time in CV studies cannot be relied upon for decisions on the allocation of funds for public projects. This is because the "dollar is a dollar" rule does not hold for welfare estimates elicited using alternative payment modes. Secondly, the evidence on the quality of survey responses under monetary and non-monetary payment modes from CV studies are inconclusive. Larson et al. (2004) found that in CV the mean standard error of WTP in money terms was $\$ 1.29$, while the mean standard error of WTP in terms of time was $5.93 \mathrm{~h}$. This implies that the willingness to pay time is noisier than the willingness to pay money because the latter is a more familiar mechanism for value expression than former. In a similar test of uncertainty in CV, Pondorfer and Rehdanz (2015) compare the uncertainties in stated willingness to contribute time and money for a local public good using CV and find that the uncertainty is reduced when WTP is elicited in labour rather than in money.

Few choice experiments have assessed the effects of payment options. Gyrd-Hansen and Skjoldborg (2008) compare the reactions to out-of-pocket payments with tax payments. The results indicate that the opposition towards out-of-pocket payments is more pronounced than in tax payments. In addition, it was found that focus shifted from the quality attributes and this could induce higher levels of random error. However, it is not possible to link these shifts in quality attributes to changes in preferences as scale parameter is confounded with parameter estimates (see Hess and Rose, 2012). The present study contributes to the existing applications on the use of non-monetary payment vehicles in stated preference elicitation by examining the effects of different numeraires on survey responses in choice experiments in a developing country context. The specific aim is to assess uncertainties among money, labour time and harvests payment modes in using split sample choice experiments on the demand for a private good (i.e. flood insurance) among smallholder farmers in a developing country. The choice of private good is to provide the minimum levels of market distortions against which to evaluate differences in uncertainties among the three payment modes. The choice of these non-monetary payment modes were informed by the applications in the literature in which labour time and harvest are adopted to elicit preferences in stated preference surveys. Furthermore, the purchase of insurance using labour time is one of interventions proposed to the increase the purchase of insurance for climate change adaptation (Bals et al., 2006; Oxfam America, 2012).

For the estimation, we adopt an integrated modeling framework to test for differences in relative scale parameters corresponding to the three different payment modes. In the integrated modeling framework, we jointly model choice experiments conducted on the purchase of flood insurance in which insurance premiums are required in money, labour time and harvest to allow relative scale parameters to differ among these three payment vehicles. We find that the relative scale parameters for non-monetary payment modes of labour time and harvests are lower than the relative scale for monetary payment mode. Given the similarities in context for the choice 
experiments e.g. complexities and estimations, we interpret these results to mean that these non-monetary payment modes exhibit higher degrees of uncertainties. These findings suggest that the requirements for sensitivity analyses in cost-benefit analyses using nonmonetary welfare estimates from stated preferences are higher. This is mainly because the responses under these non-monetary payment modes are noisier.

The rest of the paper is structured as follows: Section 2 presents the derivation of welfare under multiple constraints and section 3 focusses on the integrated econometric modelling of choice experiments under multiple payment modes. This is followed by a description of the study area and the design of the choice experiments in section four. Section 5 presents the results from the choice experiments, and section six concludes.

\section{Welfare estimates under monetary and non-monetary payment modes}

Non-monetary payment is a common method for mobilizing resources for natural resource management in many countries. Many people make non-monetary payments each year to support such causes as environment. In addition, national programmes such as working-for-water in South Africa require communities to commit labour to eradicate invasive alien species. Similarly, national programmes exist in Ghana and Rwanda to mobilize non-monetary resources to support environmental cleanliness. Furthermore, there are calls to require the payment of insurance premiums in both monetary and in-kind premiums (Ahuja and Jutting, 2004; Bals et al., 2006; Oxfam America, 2012). In a stated preference study, Brouwer et al. (2008) use a two-step procedure to investigate the role of in-kind numéraires on zero monetary bids, and find that the responses from the second step indicate that $40 \%$ of these zero monetary bids switch from zero monetary bids to positive non-monetary bids. Specifically, $75 \%$ of these respondents opt for household labour, $20 \%$ opt for paying with part of their harvests, and the remaining 5\% are willing to contribute land for the construction of an embankment to alleviate flood damages. Furthermore, Rai and Scarborough (2014) also report that only 35\% elected to complete the choice experiment in monetary terms whilst $65 \%$ chose to complete the choice experiment in labour contributions. We can conclude that the adoption of non-monetary payment modes in stated preference studies in developing and emerging countries reduces the proportion of zero bids and increases the average willingness-to-pay.

Theoretically, preferences can be elicited in different payment modes (Larson et al., 2004; Eom and Larson, 2006) and this can be one way to address constraint heterogeneity in stated preferences. Phaneuf (2013) defines constraint heterogeneity to refer situations in which choices of respondents depend on multiple constraints; and income constraint is one of these constraints. Since harvest (i.e. rice) can easily be converted into money income, the derivation of welfare measures can easily be handled within the single income constraint models. With this simplification, we adopt the framework in Larson and Shaikh (2001), and Eom and Larson (2006) to derive welfare measures for money and labour under the two constraints case. Assume that an individual consumer derives utility from the choice of four activities: consumption activities $\left(c_{i}\right)$; labour supply $\left(z_{i}\right)$; leisure $\left(l_{i}\right)$ and working for flood insurance $\left(h_{i}\right)$ in addition to flood insurance $(q)$ which is exogenously determined. The consumer chooses these activities to maximize utility subject to income and time constraints. The money price of the consumption good is $p_{c}$, the money price of leisure is $p_{l}$, the money price of insurance work is $p_{h}$ and the money cost of labour supply is $w$.

With the above notations, we can formally write the utility function of the individual as $u\left(c_{i}, l_{i}, h_{i}, q\right)$ and the utility function satisfies the following properties: $\partial u(\cdot) / \partial c_{i}>0, \partial u(\cdot) / \partial l_{i}>0 ; \partial u(\cdot) / \partial h_{i}>0$ and $\partial u(\cdot) / \partial q>0$. One main problem with the use of multiple prices is path-dependency problem in which the order in which prices change can affect the welfare measures (Johansson, 1991, 1996) and this imposes additional restrictions on the utility functions. The two utility functions with required properties to address the pathdependency problem are homothetic and quasi-linear utility functions (Johansson, 1991). The money budget constraint is $E_{i}+w z_{i}=$ $p_{c} c+p_{l} l_{i}+p_{h} h_{i}$ with $E_{i}$ being the other income in addition to wage income. The time constraint is $T_{i}=z_{i}+l_{i}+h_{i}+c_{i}$. In addition to these two constraints, we impose a minimum insurance work $\hbar \geq 0$. With this, the insurance work constraint becomes $h \geq \hbar$. The objective of the consumer is to maximize the utility subject to the above three constraints. With some adjustments, we can write the Lagrangian of optimization problem (Eom and Larson, 2006) as:

$$
L=u\left(c_{i}, l_{i}, h_{i}, q\right)+\lambda\left(E_{i}+w z_{i}-p_{c} c-p_{l} l_{i}-p_{h} h_{i}\right)+\mu\left(\left(T_{i}-\hbar\right)-l_{i}-h_{i}-c_{i}\right)+\eta(h-\hbar)
$$

The first-order necessary conditions are given by the following:

$$
\begin{aligned}
& \frac{\partial L}{\partial z}=\lambda w-\mu=0 \\
& \frac{\partial L}{\partial c}=u_{c}(\cdot)-\lambda p_{c}-\mu=0 \\
& \frac{\partial L}{\partial l}=u_{l}(\cdot)-\lambda p_{l}-\mu=0 \\
& \frac{\partial L}{\partial h}=u_{h}(\cdot)-\lambda p_{h}-\mu+\eta=0
\end{aligned}
$$

The above first-order necessary conditions are easy to interpret. Equation (2) can be re-written as $\lambda / \mu=w$ and this means that the marginal value of time is the wage rate. Similarly, we can rewrite equations (3) and (4) as $u_{c}(\cdot) / \lambda=p_{c}+w$ and $u_{l}(\cdot) / \lambda=p_{l}+w$ 
respectively. These conditions equate the marginal cost of consumption and leisure with their respective full marginal costs. Finally, equation (4) means the marginal cost of insurance work is equal to marginal value of insurance work time when $u_{h}(\cdot) / \lambda=p_{h}+w-\varpi$ with $\varpi=\eta / \lambda$ being the value of saving insurance work time. For the value of insurance work time to be positive and less than the value of time for other uses of time requires that we impose the assumption that the constraints are continuously binding with $\mu>\eta>0$ (see Eom and Larson, 2006). This is equivalent to $w>w-\varpi>0$. These assumptions impose restrictions on the arguments for both indirect utility functions and demand functions (Larson and Shaikh, 2001). Eom and Larson (2006) build on these to argue that these restrictions are met when full prices and full budget are the arguments of demand and indirect utility functions. The concept of full prices entail both the money prices of activities and their time prices converted using the corresponding shadow value of time. Also, the full budget comprises money income in addition to the shadow value of each time constraint. We can now state the indirect utility function in the form $V\left(p_{c}^{F}, p_{l}^{F}, p_{h}^{F}, M^{F}, q\right)$ where $p_{c}^{F} \equiv p_{c}+w, p_{l}^{F} \equiv p_{l}+w, p_{h}^{F} \equiv p_{h}+(w-\varpi)$ and $M^{F} \equiv E+w T-\varpi \hbar$. The specification of indirect utility function in full prices and full budget can now be used to derive willingness-to-pay in different scarce resources.

The path-dependency problem restricts the analyses of changes in prices using Hicksian demand conceptions and for this, one must assume that the expenditure function is twice differentiable (Johansson, 1996). We adopt the framework of Eom and Larson (2006) to derive the Hicksian compensating surplus for the two-constraint model in which both time and money as scarce. Following this, we derive the Hicksian compensating surplus measure of willingness to pay in money for flood insurance as:

$$
V\left(\mathbf{p}^{F}, E+w T-\eta \hbar-W T P_{m}, q_{1}\right) \equiv V\left(\mathbf{p}^{F}, E+w T-\eta \hbar, q_{0}\right)
$$

where $V(\cdot)$ is the indirect utility function; $q_{0}$ is the status quo of flood insurance; $q_{1}$ refers to some qualitative improvement in flood insurance; $W T P_{m}$ is the willingness to pay for the flood insurance, $\mathbf{p}^{F}$ is the vector of full prices. The willingness-to-pay in labour time can be derived in the same way. In this case, the willingness to pay in time represents a payment if the time being increased is less valuable to the individual (Eom and Larson, 2006). This is because the individual must accept an increase in time in exchange for the flood insurance and this must require a reduction in time for consumption, leisure and labour time. The willingness to pay additional time, $W T P_{t}$, can be defined as time compensating surplus implicitly (Eom and Larson, 2006) as:

$$
V\left(\mathbf{p}^{F}, E+w T-\eta\left(\hbar+W T P_{t}\right), q_{1}\right) \equiv V\left(\mathbf{p}^{F}, E+w T-\eta \hbar, q_{0}\right)
$$

Analogously, the willingness to pay in harvest can be derived using the indirect utility function. In this case, the harvest willingness to pay, $W T P_{r}$, can be stated as:

$$
V\left(\mathbf{p}^{F}, E+w T-\eta \hbar-p_{r} W T P_{r}, q_{1}\right) \equiv V\left(\mathbf{p}^{F}, E+w T-\eta \hbar, q_{0}\right)
$$

where $p_{r}$ is the price of the harvest.

It must be noted that the indirect utility functions can be inverted to generate the minimum expenditure function instead. For instance, one can derive from equation (6), the money willingness to pay can stated as:

$$
M^{F}-W T P_{m}=g\left(\mathbf{p}^{F}, q_{1}, V_{0}\right)
$$

The corresponding willingness to pay in time and harvest can derived from equations (7) and (8) respectively. Since RHS of equation (9) is the same for all the three payment modes, we can state the equality among the three payment modes as:

$$
M^{F}-W T P_{m}=M^{F}-\eta W T P_{t}=M^{F}-p_{r} W T P_{m}
$$

From equation (10), one can easily see that the relationship between $W T P_{m}$ and $W T P_{t}$ is $W T P_{m} / W T P_{t}=\eta$. The relation between $W T P_{m}$ and $W T P_{r}$ is $W T P_{m} / W T P_{r}=p_{r}$. However, market imperfections could distort the relationship between these willingness to pay values. For instance, labour market failure could result in situations in which $W T P_{m} \neq \eta W T P_{t}$ just as imperfections in rice market will result in $W T P_{m} \neq p_{r} W T P_{r}$.

\section{Choice modelling of alternative payments modes}

In this study, we use discrete choice experiments (DCEs) to elicit preferences for reductions in flood risk and attributes of flood insurance. In DCEs, respondents are presented with a series of choice tasks. The choice set consists of two (2) or more alternatives, which are described by attributes and their levels. The respondents then choose their preferred alternative in each choice task. Despite the hypothetical nature of these tasks, Vossler et al. (2012) has found that incentives are preserved in these choices. For the specification of the utility function for flood insurance, we follow Brouwer et al. (2014) to assume that the purchase of flood insurance follows a randomparameter error components specification of the utility function. The random-parameter error components model caters for interalternative correlation between alternatives. The random-parameter specification of utility function combines both the random parameter and error components, and this addresses the problems of independence of irrelevant alternative (IIA) and unobserved heterogeneity (Scarpa et al., 2005). The modelling framework for the random parameter error components model (RP-ECM) of Scarpa et al. (2005) provides a convenient way of capturing the changes the non-SQ alternatives provide relative to the SQ as these changes may not share the same preference structure. Biases are expected when this SQ effect are ignored. As a result, Scarpa et al. (2005) proposes ECM specification with SQ alternative-specific constant.

Under the choice modelling framework, the utility from purchasing the flood insurance, based on the notion that utility is derived from attributes (Lancaster, 1966). With this, we can specify the utility function for money, labour and harvest respectively as: 


$$
\begin{aligned}
& U_{n i t}=\nabla_{m}\left(b x_{n i t}+\beta_{m} m_{n i t}\right)+\varepsilon_{i}+e_{n i t} \\
& U_{n i t}=\nabla_{l}\left(b x_{n i t}+\beta_{l} l_{n i t}\right)+\varepsilon_{i}+e_{n i t} \\
& U_{n i t}=\nabla_{r}\left(b x_{n i t}+\beta_{r} r_{n i t}\right)+\varepsilon_{i}+e_{n i t}
\end{aligned}
$$

Equation (11) denotes utility from flood insurance under monetary payment; equation (12) is for utility from flood insurance under labour payment mode and equation (13) denotes utility from flood insurance under harvest payment mode. In equations (11)-(13), $U_{\text {nit }}$ refers to the utility for respondent $n$ for alternative $i$ at choice occasion $t, x$ denotes non-price attributes of the flood insurance including the alternative specific constant (asc), $b$ is the taste parameters for the non-price attributes, $m$ is the monetary insurance premium, $\beta_{m}$ is the marginal (dis)utility of money, $l$ is the labour time insurance premium, $\beta_{l}$ is the marginal (dis)utility of labour time, $r$ is the harvest (here: rice) insurance premium, $\beta_{r}$ is the marginal (dis)utility of harvest, $\nabla_{m}, \nabla_{l}$ and $\nabla_{r}$ are scale parameters for monetary, labour time and harvest payment modes respectively, and $e$, are the unobserved utility components which are assumed to be independently and identically type I extreme value distributed (Gumbel). The error component, $\varepsilon$, is distributed $N\left(0, \sigma^{2}\right)$. With a comparable magnitude of reductions in flood risk or transfer of risk, an integrated choice modelling framework can combine the three alternative payment modes for the joint estimation of WTP values under multiple resource constraints. The integrated framework is informed the fact that presence of all attributes in choice experiments is only required for simplification (Manski, 1977). The integrated utility function combining the above three utility functions and correcting for scale parameter differences can be specified as:

$$
U_{n i t}=\nabla\left(b x_{n i t}+\beta_{m} m_{n i t} i_{m}+\beta_{l} l_{n i t} i_{l}+\beta_{r} r_{n i t} i_{r}\right)+\varepsilon_{i}+e_{\text {nit }}
$$

$i_{l}$ is an indicator variable taking on the value of 1 if for labour insurance premium and zero otherwise, and $i_{r}$ is an indicator variable which takes a value of 1 for a rice insurance premium and zero otherwise. The relative scale parameter is defined as $\nabla=\left(\nabla_{m}\left(1-i_{l}-i_{r}\right)+\right.$ $\left.\nabla_{l} i_{l}+\nabla_{r} i_{r}\right) / \nabla_{m}$

Since preferences elicited in different numeraires can be related within a utility-consistent model of choice (Larson et al., 2004), the choices under different payment modes can pooled in a joint estimation. The joint estimation procedure offers a number of advantages (Adamowicz et al., 1994). First, the joint estimation adds more information by providing more data points. In addition, the relative scale parameters can be estimated under the joint estimation. The introduction of relative scale parameters homogenizes the variance components (Adamowicz et al., 1994). Furthermore, combining responses to choices under different environmental quality and different metrics for payment provides a more complete perspective (Larson et al., 2004). Given that presenting all the three payment modes to respondents in a choice experiments can add further choice task complexity, we choose to present a given payment metric to a respondent. In CV study, Larson et al. (2004) provides all respondent with the complete set of payment metrics. The main problem with this is that the order of changes in prices affect the welfare measure because of the path-dependency problem. As compared to specifications of utility functions in which all attributes are observed for some alternatives and decision makers, the specification of utility function in equation (3) allows for the exclusion of some of the attributes from some of the alternatives and decision makers. This framework is also similar to the one adopted in Gyrd-Hansen and Skjoldborg (2008) to disentangle the impact of payment vehicle per se from the price effects in choice experiment. Similarly, Hess et al. (2012) assess the consistency and fungibility of monetary valuations in transport. In addition to valuation and choosing issues, Hess et al. (2012) consider concerns raised by using two separately collected studies to infer trade-offs; and this is addressed by using data collected from the same respondents in the same survey. In our study, we use a homogeneous sample of smallholder irrigation farmers who engage in similar economic activities and live in the same communities with the same market opportunities.

To further simplify equation (14), we redefine both price and non-price attributes to be $z$, taste parameters including the alternative specific constant as $\alpha$ and specify the utility functions for the alternatives in the choice experiment as:

$$
U_{n i t}=\nabla \alpha z_{n i t}+\varepsilon_{i}+e_{n i t}
$$

With a panel of $T$ discrete choices for each respondent $n$, the joint probability of sequence of $\mathrm{T}$ choices $\left\{y_{1}, y_{2}, y_{3}, \ldots, y_{T}\right\}$ by an individual is given (see Marsh et al., 2011) as:

$$
P\left(y_{1}, y_{2}, \ldots, y_{T}\right)=\iint_{\alpha} \prod_{\varepsilon}^{T} \frac{\exp \left(\nabla \alpha z_{i t}+\varepsilon_{i}\right)}{\sum_{j} \exp \left(\nabla \alpha z_{j t}+\varepsilon_{j}\right)} \varphi\left(\varepsilon \mid \sigma^{2}\right) f(\alpha \mid \theta) d \varepsilon d \alpha
$$

Note that the above formulation of utility functions and probability follows Scarpa et al. (2008) in which the error component is placed on the SQ alternative as compared to Walker et al. (2007) in which the error components can be placed on non-SQ alternatives. The integral from equation (5) does not have closed-form. However, it can be simulated by averaging over a number of draws from assumed distribution (Revelt and Train, 1998). In our study, this is approximated in the log-likelihood function by numerical simulation by using 500 Halton draws.

A number of choice experiments have analyzed factors that could affect the scale parameters and explore the implications of these results for the quality of survey responses. Louviere and Eagle (2006) find that the scale parameter is inversely related to the variance of the idiosyncratic error term. This means that if the scale parameter increases, then the deterministic part of utility is assigned a greater weight relative to the unexplained component of utility. Alternatively, if the scale parameter decreases, then the deterministic part of 
utility is assigned lower weight relative to the error term. The increased scale parameter is interpreted as evidence of more determined choices and this corresponds with less random choices. Swait and Louviere (1993) list the omission of relevant variables from the specification of the utility function and choice task complexity (i.e. higher number of alternatives and attributes) to lead to more random choices. In addition, Hess and Rose (2012) note that the scale parameter is confounded with the deterministic component of utility. Specifically, the scale is inversely related to the error variance within the choice data. Therefore, a larger error variance leads to smaller parameters of the deterministic component of the utility and vice versa. Furthermore, Liebe et al. (2015) use scale parameters to test for differences in survey quality and implicit prices between two mobile devices in web choice experiments. They find that the relative scale parameters for surveys conducted using tablets and smartphone do not differ. In a recent paper, Hess and Train (2017) reiterates the impossibility of disentangling the scale parameter from preference heterogeneity; and suggest that variations in the scale parameter may arise from differences in unincluded factors e.g. correlations among the attributes.

\section{Study area and the design of choice experiments}

We undertake the present study among smallholder irrigation rice farmers at Weta/Afife Irrigation Scheme (WAIS) in the Volta River Basin in Ghana. Currently, the Ghana Irrigation Development Authority manages WAIS. Since the 1980s, the devolution of natural resource management has been an important government policy in Ghana especially in the management of irrigation schemes (see Ofori, 2000). This could be linked with structural adjustment programme during which project management were required to recover user fees from farmers to pay for the costs of pumping irrigation water (Amanor, 2015). Under devolution, communities are required to make monetary and non-monetary payments to support natural resource management. Different payment options for maintaining irrigation infrastructure have been implemented in WAIS (see Vondolia et al., 2014). Agbanyo (2012) finds that labour is a costly factor of production among farmers at WAIS since labour costs take significant component of production costs. This could account for the highly mechanized farming in which farmers adopt labour-saving technologies such as tractors and harvesters to reduce the cost of production.

Data on demand for flood insurance is not readily available (see Cummins and Mahul, 2009). Therefore, we elicited preferences for reductions in flood risk as well as attributes of flood insurance using hypothetical choices of farmers in a choice experiment. The data collection started with focus group discussions in July 2015. During the focus group discussions, discussions were held with the management of the WAIS and farmers concerning natural disasters that affect irrigation farming in the study area. Flood disaster was identified to be relevant. In addition, the focus group discussions and literature were used to identify attributes for the purchase of flood insurance. The pilot and main surveys were conducted from November 2015 to February 2016. We used face-to-face interview since other survey administrations modes (e.g. phone, internet and mail, etc.) are not possible (see Durand-Morat et al., 2016). For the main survey, irrigation rice farmers were randomly selected from communities/villages and farms. In total, we interviewed 398 irrigation farmers: 132 of these respondents were required to pay flood insurance premium with the labour time, 133 of these respondents were asked to pay flood insurance premium with harvest (rice) and 133 of these respondents were to pay a monetary insurance premium. Each respondent makes 12 hypothetical choices in the three choice experiments.

The survey was revised three times before the priors were used to generate efficient design for the MNL model. Efficient designs for the MNL model are sufficient for the estimation of panel mixed logit models (see Bliemer and Rose, 2010). The design was created using Ngene (ChoiceMetrics, 2014). The attributes and attribute levels are presented in Table 1. Five attributes define each alternative, and each attribute has three levels. The attributes were based on focus group discussions among the farmers and Brouwer et al. (2014). Since we allow the farmers to assist in identification of relevant attributes, a number of attributes such as provider of the insurance scheme were not included among the attributes. However, during the focus group discussions and the main survey, the general assumption is that the government is the provider of the hypothetical flood insurance. In addition, we also assume that flooding incidence destroys rice yields. This is likely to be the case when rice yields are submerged for longer days (see Dar et al., 2013). The final attributes are:

i. Flood occurrence - refers to the number of years it will take a flood incidence to recur, and this has three levels of 6,8 and 10 years. These levels may be justified based on the natural cycle for the occurrence of El Nino and El Nina (see e.g. Cai et al., 2014).

ii. Insurance coverage - the number of bags of $50 \mathrm{~kg}$ of rice that insurance company will pay if flood disaster occurs. The attribute levels are 12 bags, 21 bags and 30 bags.

iii. Probability of flood damage - refers to how likely a farmer is affected by flood. This attribute is presented as the number of farmers affected by flood out of every 6 farmers. The three levels identified are two (2) in about every 6 farmers, three (3) in about every 6 farmers and four (4) in about every 6 farmers. These levels were informed by discussions with extension officers at WAIS that 5 out of the 11 sections are flood prone.

Table 1

Attributes and attribute levels in the choice experiment.

\begin{tabular}{|c|c|c|c|c|c|c|c|}
\hline Attribute & Plot size (ha) & Flood occurence & Probability of damage & $\begin{array}{l}\text { Coverage } \\
\text { (per ha) }\end{array}$ & $\begin{array}{l}\text { Monetary premium } \\
\text { (GHS) }\end{array}$ & $\begin{array}{l}\text { Labour premium } \\
\text { (Hours) }\end{array}$ & $\begin{array}{l}\text { Rice premium } \\
\text { ( } 50 \mathrm{~kg} \text { bag) }\end{array}$ \\
\hline Level 1 & 1 & Once in every 6 years & 2 in every 6 farmers & $12(50 \mathrm{~kg})$ bags & 150 & 15 & 2 \\
\hline Level 2 & 2 & Once in every 8 years & 3 in every 6 farmers & $21(50 \mathrm{~kg})$ bags & 300 & 30 & 4 \\
\hline Level 3 & 3 & Once in every 10 years & 4 in every 6 farmers & $30(50 \mathrm{~kg})$ bags & 450 & 45 & 6 \\
\hline
\end{tabular}


iv. Cost of purchasing the flood insurance per ha, which is stated in money (in Ghana Cedis, GHS), rice (number of $50 \mathrm{~kg}$ bags) and in labour working hours. Each of these modes of insurance premium has three identical levels of $150 \mathrm{GHS}{ }^{1}(\approx 15 \mathrm{~h} \approx 2(50 \mathrm{~kg})$ bags of rice), $300 \mathrm{GHS}(\approx 30 \mathrm{~h} \approx 4(50 \mathrm{~kg})$ bags of rice) and $450 \mathrm{GHS}(\approx 45 \mathrm{~h} \approx 6(50 \mathrm{~kg})$ bags of rice) per ha. The market exchange rates were used in the conversion and the exchanges rates were pretested in the pilot surveys as well.

In addition to these attributes, we introduce plot size to fix the context for the purchase of flood insurance. The plot size also has three levels of 1 ha, 2 ha and 3 ha, which the respondents are asked to assume they have when making the choosing among the three alternatives during the choice experiments. The average plot size is 3.87 ha (see next section). Except for the differences in the payments of insurance premium in money, labour time or harvests, all the surveys in these three subsamples are identical.

We expect that an increase in risk exposure (i.e. a reduction in flood occurrence and an increase in probability of damage occurring) will make respondents more likely to purchase flood insurance. Furthermore, we expect insurance coverage will increase with the purchase of flood insurance whilst an increase in premium (i.e. in monetary, harvest and labour time) will make respondents less likely to purchase flood insurance under the three payment modes. Samples of the a choice card each for each of the payment modes for paying insurance premium are presented in Figs. 1-3 below.

\section{Results}

In this section, we first discuss the descriptive statistics of the three sub-samples of farmers from WAIS and then discuss the results from the random parameter error components model. The emphasis of this section is on comparing the relative scale parameters for the three modes of paying for the insurance premium for the flood risk transfer. Finally, we present and discuss the marginal WTP estimates for the attributes.

\subsection{Descriptive statistics}

Table 2 presents the descriptive statistics of the sample of farmers from WAIS. The three sub-samples are identical. About $34 \%$ of the respondents are female farmers. The average age of farmers is about 48 years with about 24 years of farming experience. Slightly more than half of the farmers has more than primary education. The average household size is about 7 . Each farmer has on average 4 ha in rice farming. Average seasonal income from rice farming is slightly less than 2000 GHS. In addition to cultivation of rice, farmers cultivate vegetables, maize and cassava. Furthermore, a high proportion of these farmers engage in alternative employment; income from farming is about the same as income from alternative employment. Specifically, Vondolia et al. (2014) estimate that slightly more than 55\% of the farmers engage in alternative employment.

Although none of the farmers has purchased flood insurance, most of the farmers have enrolled into the National Health Insurance Scheme (NHIS). About $62 \%$ of the respondents indicate that they have enrolled in NHIS. There is no relationship between the NHIS and the hypothetical flood insurance that was presented in the choice experiment. Flooding of rice fields is considered by the respondents to be an important natural disaster that affects irrigation farming. On a scale from 1 to 6, with 1 indicating "not important all" and 6 indicating "very important", the average Likert score is 5.37. A high incidence of flooding appear more destructive to the farmers relative to other natural disasters. On the average, farmers had experienced flood every other year over the past 10 years. The relevance of the flooding to irrigation farming is further supported by the perceptions among the farmers that flood trends and durations are increasing. More than $70 \%$ of the farmers see the flood trends and duration to be increasing. Furthermore, the farmers think that flooding is likely to recur within the next five years. In addition, the chances of flood affecting the farmers within the next five years is equally high. Thus, the choices the farmers are requested to make here, although hypothetical should be very realistic to the farmers. As part of the survey, we sought to classify the respondents into various degrees of risk aversion based on an experiment in Binswanger (1980). Given that choice experiment is in itself repetitive, we implemented single hypothetical risk experiment. Consistent with the interpretations of Binswanger (1980), non-responses were classified as riskless choices. Responses indicate that about $39 \%$ of the respondents can be classified as risk-averse. However, this percentage appears higher among the respondents who were interviewed with monetary payment mode version of the questionnaire. This could be attributed to high non-responses to the hypothetical risk experiment recorded under labour and harvest versions of the questionnaire.

The shares of farmers who choose not to buy insurance under the three payment modes are presented in Fig. 4. The choices appear to show that all the three alternatives are equally chosen. Respondents appear to behave consistently under the three payment modes. For instance, the proportions of respondents who do not purchase the flood insurance went up under the three payment modes during the fourth, eighth and eleventh choice cards. The same patterns were exhibited under all choice occasions.

\subsection{Estimation results from the integrated random-parameter error components model}

Following Brouwer et al. (2014), we estimate the results of a random-parameter error components framework to analyse the demand for flood insurance among smallholder farmers. In order to overcome the over-identification problem, we define the error component on

\footnotetext{
1 At the time of the survey, the exchange was $1 \mathrm{GHS}=0.26$ US dollars. The price level ratio of PPP conversion factor (GDP) to market exchange rate in 2015 was 0.33 (World Bank, http://data.worldbank.org/indicator/PA.NUS.PPPC.RF?end=2015\&start=2014). This means that one requires 0.33 US dollars to buy one US dollar worth of goods in Ghana around the time of the survey.
} 


\section{\#Supposing you have 3 ha in plots}

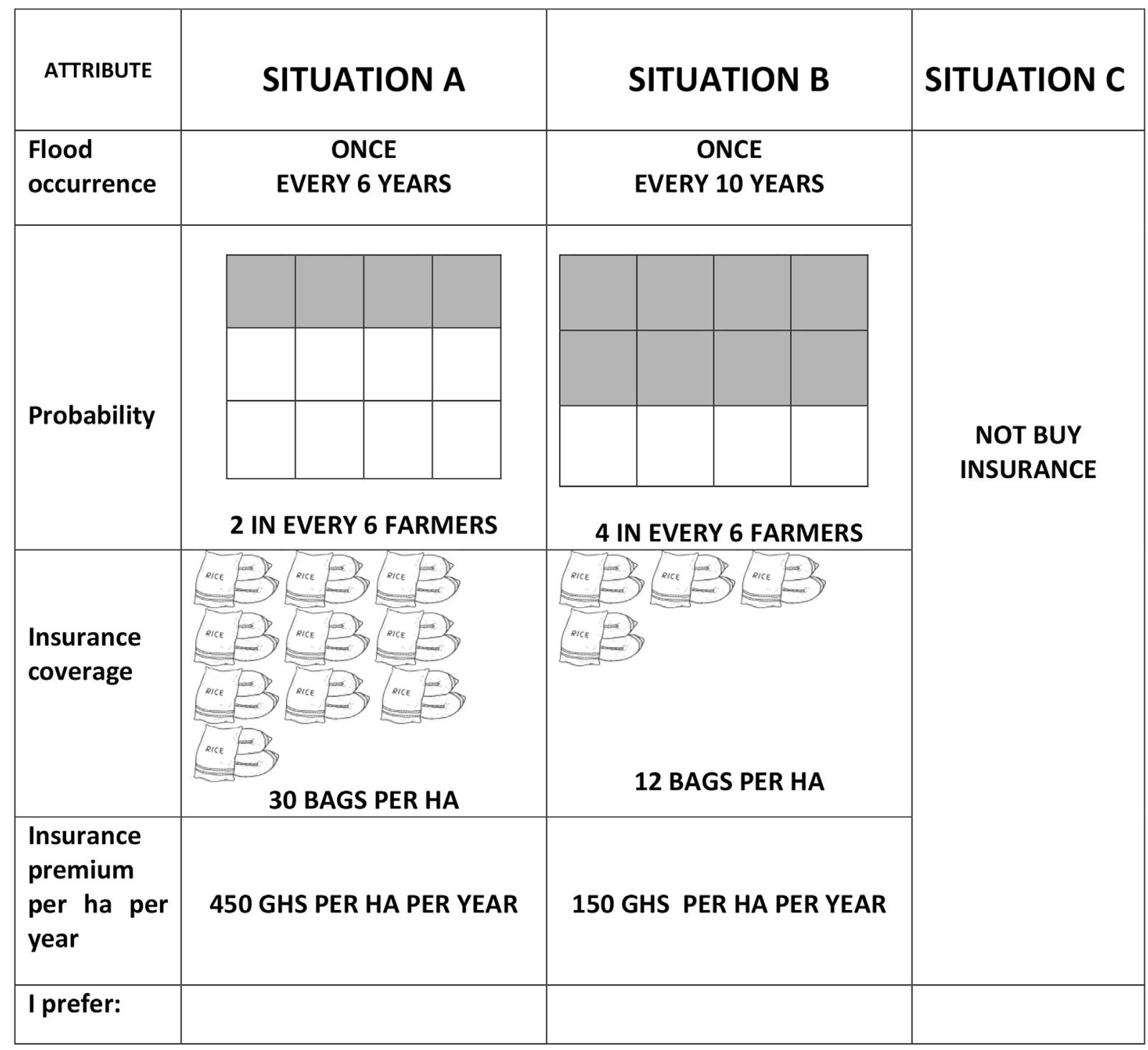

Fig. 1. A sample of choice card with payment of insurance premium in money.

the SQ alternative of not purchasing the flood insurance following Scarpa et al. (2008). That is, we fixed the variance for non-SQ alternatives at zero. Because analytical solution does not exists, we use simulated the log-likelihood function to derive the parameter values. In addition, we fix the relative scale parameter for the monetary insurance premium at 1 . The models were estimated using $\mathrm{R}$ (CMC, 2017). The results are presented in Table 3.

In Table 3, we present the results for both the multinomial logit (MNL) model and random-parameter error-components (RP-EC) model with correlations. The MNL model was only presented to assess how the RP-EC model compares with the MNL. Henceforth, we discuss only the results from the RP-EC model. The RP-EC results indicate that as flood return period increases, the likelihood of farmers purchasing flood insurance falls. This is because the mean of flood return period is negative and statistically significant. In addition to the mean of flood occurrence, the standard deviation of flood occurrence is statistically significant. This means that there is heterogeneity in preferences for increases in flood return period. The insurance coverage is positive and statistically significant meaning that 


\section{\#Supposing you have 3 ha in plots}

\begin{tabular}{|c|c|c|c|}
\hline ATTRIBUTE & SITUATION A & SITUATION B & SITUATION C \\
\hline $\begin{array}{l}\text { Flood } \\
\text { occurrence }\end{array}$ & $\begin{array}{c}\text { ONCE } \\
\text { EVERY } 6 \text { YEARS }\end{array}$ & $\begin{array}{c}\text { ONCE } \\
\text { EVERY } 10 \text { YEARS }\end{array}$ & \multirow{5}{*}{$\begin{array}{l}\text { NOT BUY } \\
\text { INSURANCE }\end{array}$} \\
\hline \multirow[t]{2}{*}{ Probability } & & & \\
\hline & 2 IN EVERY 6 FARMERS & 4 IN EVERY 6 FARMERS & \\
\hline $\begin{array}{l}\text { Insurance } \\
\text { coverage }\end{array}$ & 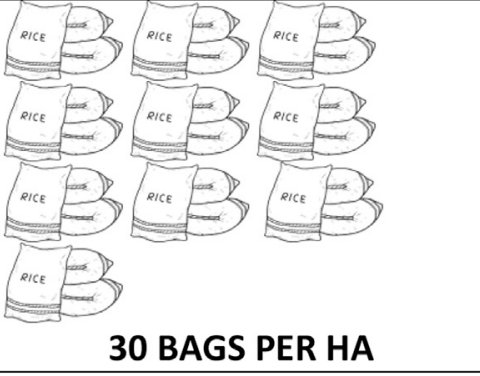 & 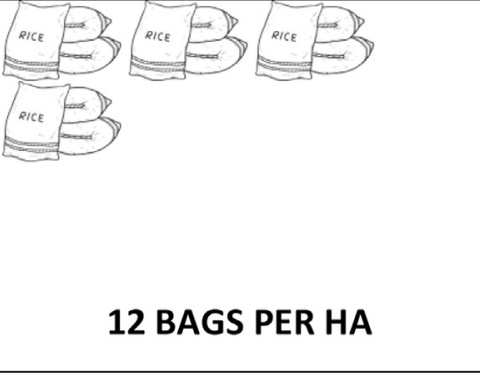 & \\
\hline $\begin{array}{l}\text { Insurance } \\
\text { premium } \\
\text { per ha per } \\
\text { year }\end{array}$ & $\begin{array}{c}6 \text { (50 KG) BAGS OF RICE PER } \\
\text { HA PER YEAR }\end{array}$ & $\begin{array}{c}2 \text { (50 KG) BAGS OF RICE PER } \\
\text { HA PER YEAR }\end{array}$ & \\
\hline I prefer: & & & \\
\hline
\end{tabular}

Fig. 2. A sample of choice card with payment of insurance premium in harvest.

the probability of purchasing flood insurance increases with the insurance coverage. Therefore, farmers are more likely to purchase flood insurance when the compensations for flood disasters are high. In addition, the standard deviation of insurance coverage is statistically significant. This implies that there is heterogeneity in preferences for insurance coverage. Both the mean and standard deviation of plot size are statistically significant. This means that the probability of purchasing insurance falls as the plot size increases. In addition, the statistical significance of standard deviation for plot size means that there is heterogeneity in the preferences for plot size. Although the mean of probability of damage is not statistically significant in the RP-EC model, its standard deviation is significant. This also means that there is heterogeneity in preferences for reductions in flood probability.

The insurance premiums, in all its three forms of monetary, labour time and harvest, are statistically at $1 \%$ level. This implies that, in accordance with economic theory, as the insurance premiums increase, the probability of purchasing flood insurance falls. This result holds for all the three modes for paying the insurance premium. The two relative scale parameters for labour time and harvest insurance 


\section{\#Supposing you have 3 ha in plots}

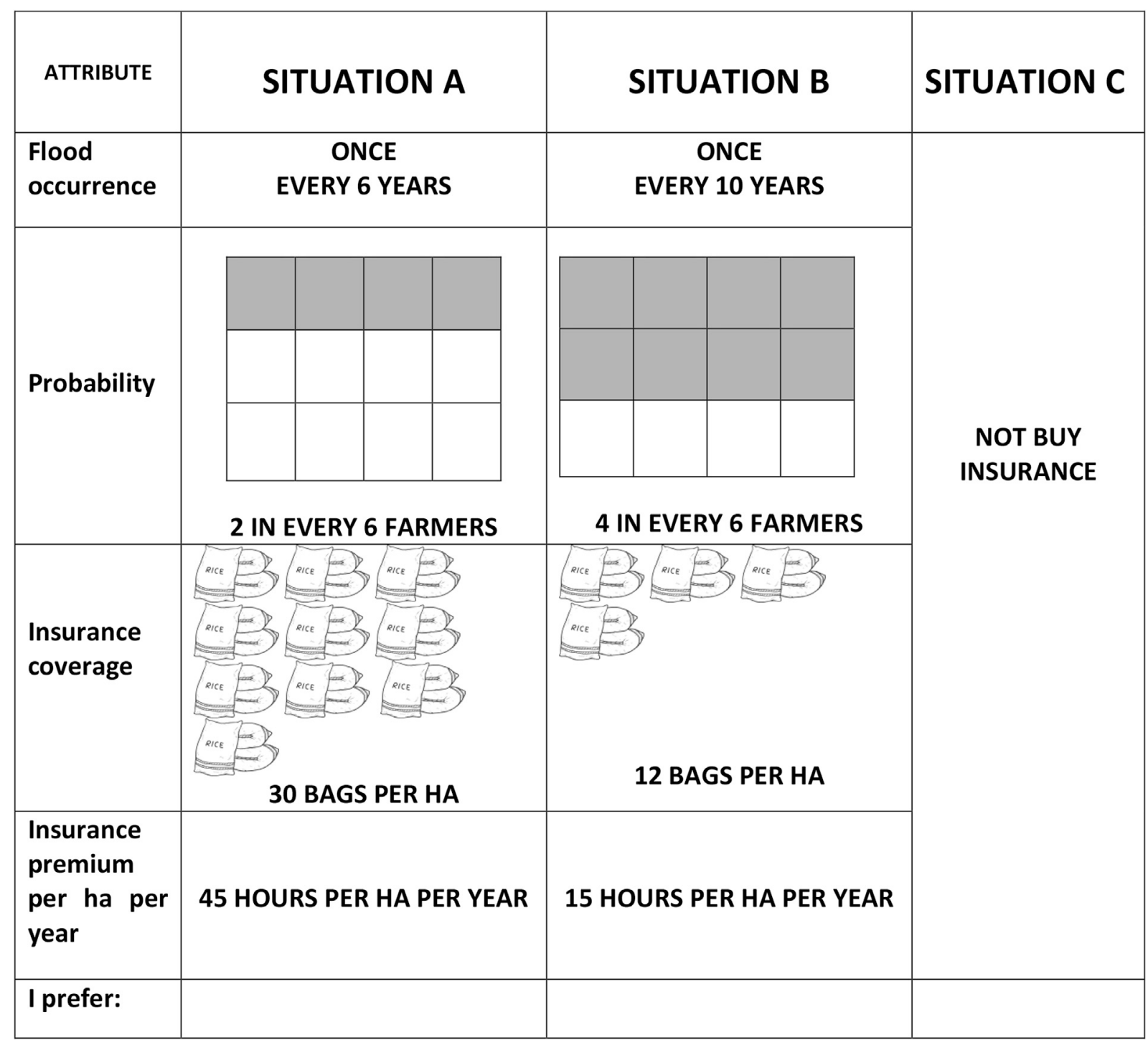

Fig. 3. A sample of choice card with payment of insurance premium in labour time.

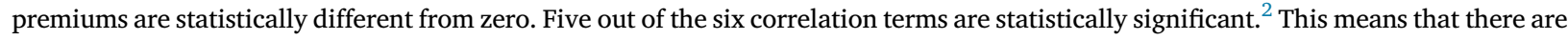
correlations among the attributes.

The specification of the random-parameter error components model is good. All the attributes that are statistically significant have the expected signs and consistent under both MNL and RP-EC models. The variance is statistically significant and the estimated total unobserved component of utility associated with alternatives gives a total variance of 100.82 . It is only the probability attribute that is not statistically significant at $10 \%$ level. Generally, processing of probability attributes is difficult in stated preferences especially among farmers in developing countries. The statistical insignificance of the probability attribute could also be due to the high probability values

\footnotetext{
${ }^{2}$ The results of correlation are not presented in Table 3.
} 
Table 2

Descriptive statistics for each of the three subsamples and total sample.

\begin{tabular}{|c|c|c|c|c|}
\hline VARIABLES & $\begin{array}{l}\text { LABOUR } \\
\text { TIME }\end{array}$ & HARVEST & MONETARY & TOTAL \\
\hline Gender ( $=1$ if female) & 0.31 & 0.36 & 0.34 & 0.34 \\
\hline Age (in years) & 49.4 & 48.01 & 47.86 & 48.43 \\
\hline Education (percentage with above primary education) & 54.33 & 62.59 & 60.16 & 59.08 \\
\hline Household size (number of household members) & 7.07 & 6.73 & 6.56 & 6.78 \\
\hline Experience in in farming (in years) & 25.13 & 25.0 & 24.04 & 24.74 \\
\hline Average rice plot size (in ha) & 4.74 & 3.56 & 3.32 & 3.87 \\
\hline Average seasonal farm income (in GHS) & 2065.62 & 2187.33 & 1593.91 & 1948.68 \\
\hline Perceptions of importance of flooding (1-6 Likert scale with $1=$ "not important at all" and $6=$ "very important") & 5.06 & 5.71 & 5.345 & 5.37 \\
\hline $\begin{array}{l}\text { Perceptions of importance of other natural disasters (1-6 Likert scale with } 1=\text { "not important at all" and } 6=\text { "very } \\
\text { important") }\end{array}$ & 4.24 & 3.91 & 4.156 & 4.10 \\
\hline Average number of flood damages in past 10 years & 5.33 & 4.85 & 5.810 & 5.32 \\
\hline Respondents who perceive flood trends to be increasing (\%) & 65.91 & 72.73 & 74.81 & 71.14 \\
\hline Respondents who perceive flood durations to be increasing (\%) & 64.12 & 74.24 & 74.05 & 70.81 \\
\hline Risk of flood occurrence in next 5 years (1-6 Likert scale with $1=$ "very unlikely" and $6=$ "very likely") & 4.82 & 5.38 & 4.857 & 5.022 \\
\hline Risk of farmer suffering flood damages (1-6 Likert scale with $1=$ "very unlikely" and $6=$ "very likely") & 4.26 & 4.83 & 4.38 & 4.49 \\
\hline Respondents identified with risk aversion (\%) & 31.06 & 33.83 & 53.38 & 39.44 \\
\hline Number of respondents & 132 & 133 & 133 & 398 \\
\hline
\end{tabular}

adopted in this study.

\subsection{Statistical tests on relative scale parameters}

From the results in Table 3, the relative scale parameters for labour time and harvest were found to be statistically significantly different from zero. Given that our intention is to test whether these non-monetary numeraires produce are more or less certain (noisier) relative to the monetary numeraire, the relevant statistical test is to test whether the relative scale parameters for labour time and harvest are statistically different from one. The test results indicate that both relative scale parameters are statistically different from 1 at $1 \%$ significance level. The corresponding t-values for relative scale parameters for labour and harvest payment modes are -13.73 and -41.81 respectively. The relative scale parameters for labour time and harvest are 0.2414 and 0.2172 respectively. This means that both relative scale parameters for the non-monetary numeraires are less than 1 . Therefore, the absolute values for the scale parameters for the non-monetary payments modes are less than the scale parameter for monetary payment for flood insurance. Given the similarities in the context for the choice experiment e.g. number of attributes, alternatives, estimation method, we interpret these results to mean that the responses under the non-monetary numeraires of labour time and harvest are more uncertain as compared to the responses under the monetary numeraire.

These findings support Larson et al. (2004) that responses in leisure time in CV are more uncertain than responses in money. We have presented the first evidence using choice experiment to document that non-monetary payment modes are more uncertain as compared to monetary payment mode. It should also be noted that we adopted a private good, that is, the purchase of a private good, flood insurance, among smallholder commercial farmers. Furthermore, we have found that the results of Larson et al. (2004) apply to another nonmonetary numeraire, harvest, which have been adopted in stated preference elicitation in developing countries (see e.g. Shyamsundar and Kramer, 1996; Brouwer et al., 2008). The reasons for the differences in scale parameters between monetary and non-monetary payment modes could be many. Among them could be the fact that although a unit of money could purchase a given unit of goods and services, a certain amount of labour time could accomplish varying degrees of tasks. In addition, for harvest, the plausible explanation could be the fluctuations in the price (valuations) of the produce within the year. This will make respondents to have different values for a unit of produce/harvest and could explain the higher variation in the use of harvest as a numeraire for stated preference elicitation. Furthermore, it can also be argued that the respondents are more familiar with monetary transactions than non-monetary exchanges and these different degrees of uses and experiences could induce different levels of uncertainties during the choice experiments.

These results have a number of implications for the conduct of stated preferences and the uses of welfare estimates from stated preferences in project evaluations in developing countries. Specifically, these results indicate that the requirements for sensitivity analyses are higher for non-monetary welfare estimates from stated preferences. Also, since non-monetary payment modes are more uncertain, requirements for precision in the framing of stated preference scenarios are more relevant. Despite the higher uncertainties of non-monetary payment modes, the behavior of respondents appear to be similar under both monetary and non-monetary payment modes. For instance, the purchases of flood insurance fall when insurance premiums are high irrespective of the payment mode. This could be attributed to stability of human preference under monetary and non-monetary payment modes.

\subsection{Marginal willingness-to-pay}

The marginal WTP values are presented in Table 4. Since all non-premium attributes are random but the premium attributes are nonrandom, the marginal WTP is simulated based on the procedure of Krinsky and Robb (1986) in which we use the means and standard deviations presented in Table 3 to generate 10000 draws. Except probability of farmer suffering damage, all the marginal WTP values presented in Table 4 are statistically different from zero at $1 \%$ significance level. The marginal WTP for insurance coverage is 11.24 GHS 


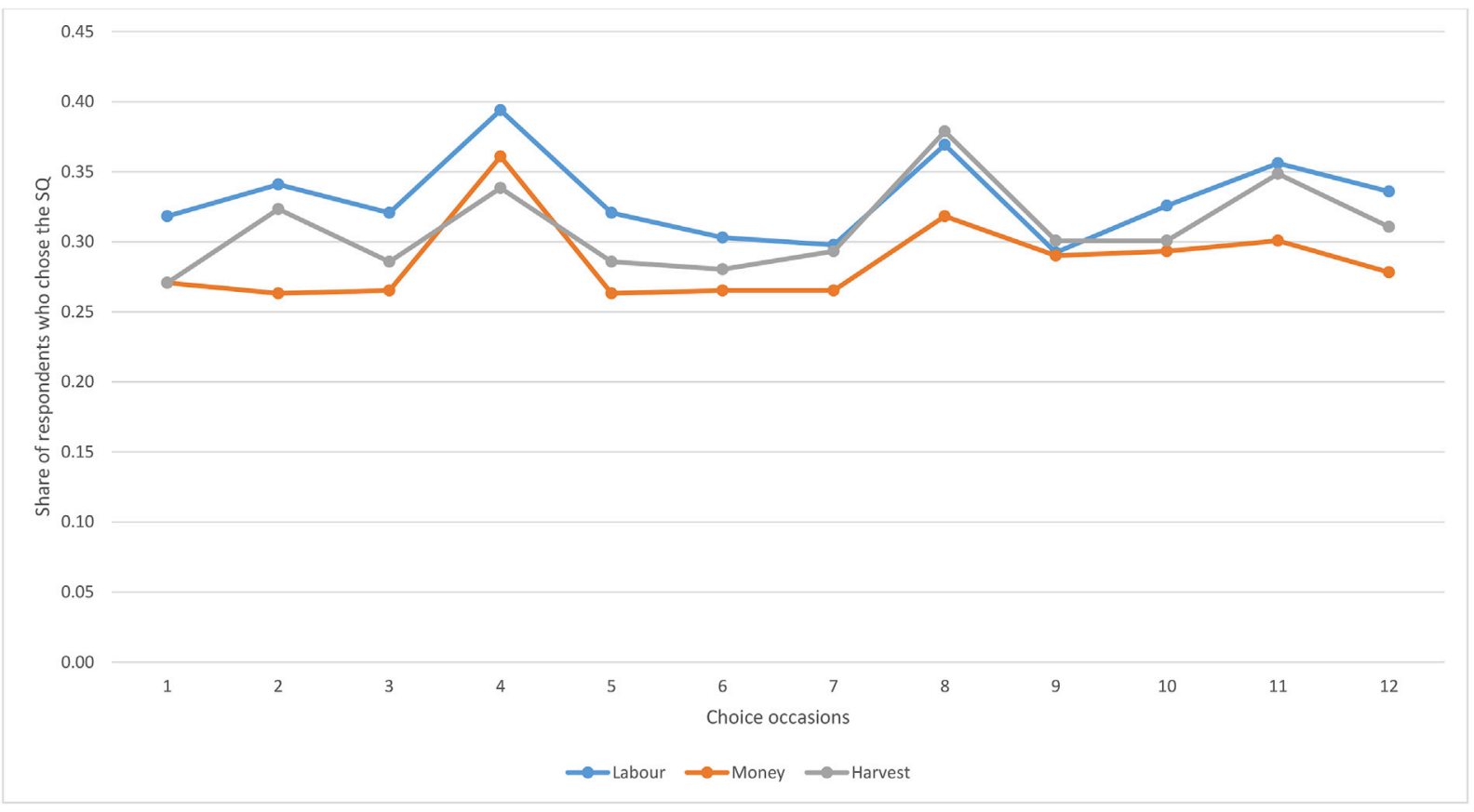

Fig. 4. The choice shares for Status Quo (SQ) alternative (i.e. no flood insurance) for the three numeraires for paying insurance premium.

Table 3

Results of integrated multinomial logit and random-parameter error-components models.

\begin{tabular}{|c|c|c|c|c|}
\hline & \multicolumn{2}{|l|}{ MNL MODEL } & \multicolumn{2}{|l|}{ RP-EC MODEL } \\
\hline & Parameter estimates & Rob. Standard errors & Parameter estimates & Rob. Standard errors \\
\hline Alternative specific constant (asc) & $-0.9072^{* * *}$ & 0.2313 & $-10.512^{* * *}$ & 1.2376 \\
\hline Interaction of asc and risk aversion & $0.9351^{* * *}$ & 0.2751 & $0.6657^{* * *}$ & 0.0859 \\
\hline Mean of plot size & -0.0688 & 0.0542 & $-0.856^{* * *}$ & 0.2921 \\
\hline Mean of flood return & $-0.1551^{* * *}$ & 0.0183 & $-0.5022^{* * *}$ & 0.0681 \\
\hline Mean of coverage & $0.0474 * * *$ & 0.0087 & $0.1409 * * *$ & 0.0267 \\
\hline Mean of probability & -0.0067 & 0.031 & -0.0062 & 0.0557 \\
\hline Premium (money) & $-0.1386^{* * *}$ & 0.0337 & $-1.251^{* * *}$ & 0.1909 \\
\hline Premium (labour) & $-0.175^{* * *}$ & 0.0366 & $-3.2258^{* * *}$ & 0.8077 \\
\hline Premium (harvest) & $-0.0407^{* * *}$ & 0.0181 & $-0.8621 * * *$ & 0.2247 \\
\hline Standard deviation of plot size & NA & NA & $-1.3836^{* * *}$ & 0.2624 \\
\hline Standard deviation of flood return & NA & NA & $-0.5406^{* * *}$ & 0.061 \\
\hline Standard deviation of coverage & NA & NA & $-0.0753^{* * *}$ & 0.0282 \\
\hline Standard deviation of probability & NA & NA & $0.2814 * * *$ & 0.0626 \\
\hline Relative scale for money (Fixed) & 1 & NA & 1 & NA \\
\hline Relative scale for labour time & $0.7623^{* * *}$ & 0.1158 & $0.2414 * * *$ & 0.0553 \\
\hline Relative scale for harvest & 0.1397 & 0.1044 & $0.2172^{* * *}$ & 0.0187 \\
\hline Sigma 1 (Fixed) & NA & NA & 0 & NA \\
\hline Sigma 2 (Fixed) & NA & NA & 0 & NA \\
\hline Sigma 3 & NA & NA & $-10.041^{* * *}$ & 0.9299 \\
\hline \multicolumn{5}{|l|}{ Model diagnostics } \\
\hline LL(final) & -5114.509 & & -2849.679 & \\
\hline $\mathrm{LL}(0)$ & -5227.197 & & -5227.197 & \\
\hline Adj. rho-sq & 0.020 & & 0.450 & \\
\hline $\mathrm{AIC} / \mathrm{n}$ & 2.154 & & 1.207 & \\
\hline $\mathrm{BIC} / \mathrm{n}$ & 2.169 & & 1.237 & \\
\hline $\mathrm{n}$ (observations) & 4758 & & 4758 & \\
\hline r(respondents) & 398 & & 398 & \\
\hline k(parameters) & 11 & & 22 & \\
\hline
\end{tabular}

***significant at $1 \%$ level.

per annum, 0.44 labour time per annum and $1.66 \mathrm{~kg}$ of rice per annum. The marginal WTP for reducing the frequency of flood by one year is $40.23 \mathrm{GHS}, 1.56$ labour hours and $5.80 \mathrm{~kg}$ of rice produce. Similarly, the marginal WTP for insuring 1 ha of rice field against flood damage is 68.22 GHS, 2.65 labour time and $9.90 \mathrm{~kg}$ of rice. The marginal WTP for reducing probability of suffering flood damage is not 
Table 4

Marginal willingness to pay in money, labour time and harvest.

\begin{tabular}{|c|c|c|c|}
\hline & $\begin{array}{l}\text { MONETARY } \\
\text { (GHS) }\end{array}$ & $\begin{array}{l}\text { LABOUR TIME } \\
\text { (HOURS) }\end{array}$ & $\begin{array}{l}\text { HARVEST } \\
\text { (KG RICE) }\end{array}$ \\
\hline PLOT SIZE & $-68.216^{* * *}$ & $-2.645^{* * *}$ & $-9.899^{* * *}$ \\
\hline FLOOD RETURN PERIOD & $40.228^{* * *}$ & $1.560 * * *$ & $5.798^{* * *}$ \\
\hline INSURANCE COVERAGE (100 kg) & $11.238^{* * *}$ & $0.436^{* * *}$ & $1.630 * * *$ \\
\hline PROBABILITY & -0.059 & -0.002 & -0.008 \\
\hline
\end{tabular}

***Significant at $1 \%$ level.

statistically significant.

\section{Conclusions}

The choice of a particular numeraires in project evaluation has been noted to affect the provision of public goods and under some circumstance the purchase of private goods. With an increasing use of non-monetary numeraires in environmental management and stated preferences elicitation in developing countries, it is important to understand the implications of preferences elicited in these nonmonetary numeraires. For these non-monetary welfare measures to be useful in project evaluation, it is relevant to know circumstance surrounding the elicitation of these preferences including the quality of survey responses under these non-monetary numeraires are comparable to those with under monetary elicitation of stated preferences. The present study contributes to the existing studies by assessing uncertainties in survey responses under non-monetary stated preference elicitation. First, we found that the behavior of respondents towards the three payment modes are similar. For instance, the shares of respondents who choose not to purchase flood insurance are the same for the three payment modes. Similarly, the purchase of insurance increases when insurance premiums are low irrespective of payment mode. Secondly, we found that relative scale parameters for non-monetary payment modes are lower than relative scale parameter for monetary payment mode. We argue that this result means that the quality of survey responses under both non-monetary stated preference elicitation are more uncertain as compared to responses under monetary stated preference elicitation. In other words, the responses under non-monetary stated preferences elicitation are noisier for both labour time and harvest than responses under monetary stated preference elicitation. Finally, we also present marginal willingness-to-pay for reductions in flood risk among farmers in a developing country.

These findings offer a number of suggestions for project evaluation and stated preferences surveys using non-monetary numeraires. For project evaluation, the findings of the present study suggest that the requirements of sensitivity analyses in project evaluations based on welfare estimates from non-monetary numeraires are higher. The findings of the present study also suggest further attempts should be made in survey design and implementation to address some of the sources of uncertainties surrounding the use of non-monetary numeraires in stated preference elicitation such as clarity on the activities that would be procured with non-monetary payments.

\section{Statement of contribution}

The paper makes an original contribution to the existing literature on the use of alternative payment modes in stated preferences with a particular emphasis on choice experiments in developing countries. Specifically, the paper makes the first contribution by using split-sample choice experiments to test whether non-monetary payment modes (i.e. labour time and harvest) are more uncertain relative to monetary payment modes. In addition, we present a framework to analyze choice experiments conducted under alternative payment modes. Furthermore, we compared marginal willingness to pay values under both monetary and non-monetary payment modes. Based on the findings, we make recommendations for the use of non-monetary payment modes for the design and implementation of choice experiments using these non-monetary payment modes in developing countries and explore the implications of these findings for the use of non-monetary welfare estimates in monetary cost-benefit analyses.

\section{Acknowledgements}

Godwin K. Vondolia acknowledges a travel grant from Terje and Valerie Stalder Jacobsens Foundation at the Arctic University of Norway. We are grateful to Emmanuel K. Adadey and Seth Vondolia for facilitating the data collection in Ghana; and to Michiel Bliemer and Stephane Hess for discussions on the choice experiment and its modelling. We thank two anonymous reviewers.

\section{Appendix A. Supplementary data}

Supplementary data related to this article can be found at https://doi.org/10.1016/j.jocm.2018.01.003.

\section{References}

Adamowicz, W., Louviere, J., Williams, M., 1994. Combining revealed and stated preference methods for valuing environmental amenities. J. Environ. Econ. Manag. 26, $271-292$.

Agbanyo, A.D.A., 2012. Rice Production and Marketing: a Comparative Study of Weta (Afife) and Avatime Traditional Areas. MPhil Thesis submitted to Institute of African Studies. University of Ghana, Legon, Accra. 
Ahlheim, M., Fror, O., Heinke, A., Duc, N.M., Dinh, P.V., 2010. Labour as a Utility Measure in Contingent Valuation Studies - How Good is it Really? Discussion Paper 13 - 2010. FZID Discussion Papers Institute of Economics, University of Hohenheim, Germany.

Ahlheim, M., Fror, O., Duc, N.M., Rehl, A., Siepmann, U., Dinh, P.V., 2017. Labour as a Utility Measure Reconsidered. Hohenheim Discussion Papers in Business, Economics and Social Sciences, No. 03 - 2017. Faculty of Business, Economics and Social Sciences, University of Hohenheim, Germany.

Ahuja, R., Jutting, J., 2004. Are the poor too poor to demand Health insurance? Journal of Microfinance 6 (1), 1-20.

Amanor, S.K., 2015. Rising powers and rice in Ghana: China, Brazil and African agricultural development. In: CBAA Working Paper 123. Future Agricultures Consortium. Institute of Development Studies, University of Sussex, Brighton.

Asquith, N.M., Vargas, M.T., Wunder, S., 2008. Selling two environmental services: in-kind payments for bird habitat and watershed protection in Los Negros, Bolivia. Ecol. Econ. 65, 675-684.

Bals, C., Warner, K., Butzengeiger, S., 2006. Insuring the uninsurable: design options for a climate change funding mechanism. Clim. Pol. 6 (6), $637-647$.

Becker, G.S., 1965. A theory of the allocation of time. Econ. J. 75, 493-517.

Binswanger, H.P., 1980. Attitudes towards risk: experimental measurement in rural India. Am. J. Agric. Econ. 62 (3), $395-407$.

Bliemer, M.C.J., Rose, J.M., 2010. Construction of experimental design for mixed logit models allowing for correlation across choice observations. Transport. Res. Part B 44 (6), 720-734.

Brekke, K.A., 1997. The numéraires matters in cost-benefit analysis. J. Publ. Econ. 64, 117-123.

Brouwer, R., Tinh, B.D., Tuan, T.H., Magnussen, K., Navrud, S., 2014. Modelling demand for catastrophic flood risk insurance in coastal zones in Vietnam using choice experiments. Environ. Dev. Econ. 19, 228-249.

Brouwer, R., Akter, S., Brander, L., Haque, E., 2008. Economic valuation of flood risk exposure and reduction in a severely flood prone developing country. Environ. Dev. Econ. 14, 397-417.

Cai, W., Borlace, S., Lengaine, M., van Rensch, P., Collins, M., Vecchi, G., Timmermann, A., Santoso, A., McPhaden, M.J., Wu, L., England, M.H., Wang, G., Guilyardi, E., Jin, F.-F., 2014. Increasing frequency of extreme El Niño events due to greenhouse warming. Nat. Clim. Change 4, 111-116.

ChoiceMetrics, 2014. Ngene 1.1.2: User Manual and Reference Guide.

CMC, 2017. CMC Choice Modelling Code for R. Choice Modelling Centre, University of Leeds. www.cmc.leeds.ac.uk.

Cummins, J.D., Mahul, O., 2009. Catastrophe Risk Financing in Developing Countries: Principles for Public Intervention. The World Bank, Washington, DC.

Dar, M.H., de Janvry, A., Emerick, K., Raitzer, D., Sadoulet, E., 2013. Flood-tolerant rice reduces yield variability and raises expected yield, differentially benefitting socially disadvantaged groups. Sci. Rep. 3 (3315) http://dx.doi.org/10.1038/srep03315.

Dreze, J., 1998. Distribution matters in cost-benefit analysis: comment on K. A. Brekke. J. Publ. Econ. 70, $485-488$.

Durand-Morat, A., Wailes, E.J., Nayga Jr., R.M., 2016. Challenges of conducting contingent valuation in developing countries. Am. J. Agric. Econ. 98 (2), 597-609.

Echessah, P.N., Swallow, B.M., Kamara, D.W., Curry, J.J., 1997. Willingness to contribute labour and money to tsetse control: application of contingent valuation in Busia District, Kenya. World Dev. 25 (2), 239-253.

Eom, Y.-S., Larson, D.M., 2006. Valuing housework time from willingness to spend time and money for environmental quality. Rev. Econ. Househ. 4, $205-227$.

Gibson, J.M., Rigby, D., Polya, D.A., Russell, N., 2016. Discrete choice experiments in developing countries: willingness to pay versus willingness to work. Environ. Resour. Econo. 65, 697-721.

Gyrd-Hansen, D., Skjoldborg, U.S., 2008. The price proxy in discrete choice experiments: issue of relevance for future research. Chapter 8. In: Ryan, M., Gerald, K., Amaya-Amaya, M. (Eds.), Using Discrete Choice Experiments to Value Health and Health Care. Springer, Dordrecht, pp. 175-193.

Hess, S., Orr, S., Sheldon, R., 2012. Consistency and fungibility of monetary valuations in transport: an empirical analysis of framing and mental accounting effects. Transport. Res. Part A 46 (2012), 1507-1516.

Hess, S., Rose, J.M., 2012. Can scale and coefficient heterogeneity be separated in random coefficients models? Transportation 39 (6), $1225-1239$.

Hess, S., Train, K., 2017. Correlation and scale in mixed logit models. Journal of Choice Modelling 23 (2017), 1-8.

Johansson, P.-O., 1996. Cost-benefit Analysis of Environmental Change. Cambridge University Press, Cambridge.

Johansson, P.-O., 1991. An Introduction to Modern Welfare Economics. Cambridge University Press, Cambridge.

Krinsky, I., Robb, A.L., 1986. On approximating the statistical properties of elasticities. Rev. Econ. Stat. 68, 715-719.

Lancaster, K., 1966. A new approach to consumer theory. J. Polit. Econ. 74 (2), 132-157.

Larson, D.M., Shaikh, S.L., Layton, D.F., 2004. Revealing preferences for leisure time from stated preference data. Am. J. Agric. Econ. 86 (2), $307-320$.

Larson, D.M., Shaikh, S.L., 2002. Empirical specification requirements for two-constraint models of recreation choice. Am. J. Agric. Econ. 83 (2), $428-440$.

Larson, D.M., Shaikh, S.L., 2001. Empirical specification requirements for two-constraint models of recreation choice. Am. J. Agric. Econ. 83 (2), $428-440$.

Lee, L., Lee, M.P., Bertini, M., Zauberman, G., Ariely, D., 2015. Money, time and stability of consumer preferences. Journal of Marketing Research LII 184-199.

Liebe, U., Glenk, K., Oehlmann, M., Meyerhoff, J., 2015. Does the use of mobile devices (tablets and smartphones) affect survey quality and choice behavior in web surveys? Journal of Choice Modelling 14, 17-31.

Louviere, J.J., Eagle, T., 2006. Confound it! that pesky little scale constant messes up our convenient assumptions. In: Proceedings of the Sawtooth Software Conference 2006.

Manski, C.F., 1977. The structure of random utility models. Theor. Decis. 8, 229-254.

Marsh, D., Mkwara, L., Scarpa, R., 2011. Do respondents' perceptions of the status quo matter in non-market valuation with choice Experiments? An application to New Zealand freshwater streams. Sustainability 2011 (3), 1593-1615.

Navrud, S., Pruckner, G.J., 1997. Environmental valuation to use or not to use? A comparative study of the United States and Europe. Environ. Resour. Econ. 10, 189-217.

Ofori, F., 2000. Economic reforms and agricultural input markets: a case study of Ghana. In: Paper presented at the International Workshop on Policy Reforms and Agricultural Input Markets: experiences, Lessons, and Challenges, Cape Town, South Africa, October 16-20, 2000.

O'Garra, T., 2009. Bequest values for marine resource: how important for indigenous communities in less-developed economies. Environ. Resour. Econ. 44, 179-202. Oxfam America, 2012. Horn of Africa Risk Transfer for Adaptation. Oxfam America, Boston.

Phaneuf, D.J., 2013. Heterogeneity in environmental demand. Annual Review of Resource Economics 5, $227-244$.

Pondorfer, A., Rehdanz, K., 2015. Eliciting Preferences for Public Goods in Non-monetized Communities: Accounting for Preference Uncertainty. No. 2010, October 2015, Kiel Working Papers. Kiel Institute of the World Economy, Kiel, Germany.

Rai, R.K., Scarborough, H., 2013. Economic value of mitigation of plant invaders in a subsistence economy: incorporating labour as a mode of payment. Environ. Dev. Econ. 18 (02), 225-244.

Rai, R.K., Scarborough, H., 2014. Nonmarket valuation in developing countries: incorporating labour contributions in environmental benefits estimates. Aust. J. Agric. Resour. Econ. 59, 479-498.

Revelt, D., Train, K., 1998. Mixed logit with repeated choices: households' choices of appliance efficiency level. Rev. Econ. Stat. 80 (4), 647-657.

Scarpa, R., Ferrini, S., Willis, K., 2005. Performance of error component models for status quo effects in choice experiments, chapter 13. In: Scarpa, Ricardo, Alberini, Anna (Eds.), Applications of Simulation in Environmental and Resource Economics. Springer, Dordrecht, pp. $247-273$.

Scarpa, R., Thiene, M., Train, K., 2008. Utility in Willingness to Pay Space: a tool to address the confounding random scale effects in destination choice to the Alps. Am. J. Agric. Econ. 90 (4), 994-1010.

Shyamsundar, P., Kramer, R.A., 1996. Tropical forest protection: an empirical analysis of the costs borne by local people. J. Environ. Econ. Manag. 31 (2), 129-144.

Swait, J., Louviere, J.J., 1993. The role of the scale parameter in the estimation and comparison of multinomial logit models. J. Market. Res. 30 (3), 305-314.

Swallow, B.M., Woudyalew, M., 1994. Evaluating willingness to contribute to a local public good: an application of contingent valuation to tsetse control in Ethiopia. Ecol. Econ. 11, 153-161.

Vondolia, G.K., Eggert, H., Navrud, S., Stage, J., 2014. What do respondents bring to Contingent Valuation? A Comparison of monetary and labour payment vehicles. Journal of Environmental Economics and Policy 3 (3), 253-267. 
Vossler, C., Doyon, M., Rondeau, D., 2012. Truth in consequentiality: theory and field evidence on discrete choice experiments. American Economic Journal 4 (4), $145-171$.

Walker, J.L., Ben-Akiva, M., Bolduc, D., 2007. Identification of parameters in normal error component logit-mixture (NECLM) models. J. Appl. Econom. 22, 1095-1125.

Whittington, D., Mu, X., Roche, R., 1990. Calculating the value of time spent collecting water: some estimates for Ukunda, Kenya. World Dev. 18 (2), 269-280.

Whittington, D., 2010. What have we learned from twenty years of stated preference studies in less developed countries? Annual Review of Resource Economics 2 , 209-236. 